Original Research Article

\title{
Drug utilization pattern in pregnancy at a tertiary care hospital in Puducherry: a cross sectional observational study
}

\author{
Nitya Selvaraj ${ }^{1}$, Anugraha Sekar ${ }^{2}$, Ramya Gandhi $^{3 *}$, Nalinidevi Jayabalan ${ }^{1}$, Suganya Ganesan$^{1}$, \\ Meher Ali Raja Mohammad ${ }^{1}$
}

${ }^{1}$ Department of Pharmacology, ${ }^{2}$ MBBS Student, ${ }^{3}$ Department of Pathology, Sri Manakula Vinayagar Medical College and Hospital, Puducherry, India

Received: 12 February 2018 Accepted: 12 March 2018

*Correspondence to: Dr. Ramya Gandhi, Email: ramya2path@ yahoo.co.in

Copyright: (C) the author(s), publisher and licensee Medip Academy. This is an openaccess article distributed under the terms of the Creative Commons Attribution NonCommercial License, which permits unrestricted noncommercial use, distribution, and reproduction in any medium, provided the original work is properly cited.

\begin{abstract}
Background: Drug utilization pattern in pregnancy population provide insights regarding drug profile and interventional measures and also minimizes the inherent risk occurring due to unethical prescription.

Methods: It was a prospective cross sectional study where prescription slips were collected. Further drugs were categorized according to the classification defined by US Food and drug Administration for pregnancy. Using Pre validated questionnaire the pregnant women were interviewed and parameters regarding knowledge about antenatal visit and contraception, self-medication practices were noted.

Results: Among the total 365 participants, $81.4 \%$ had finish their high schooling and were in reproductive age group of 22-25. Study revealed predominant usage category- A drugs in I (95.5\%), II (97.8\%), III (96.4\%) trimester. None of them received Category D or X drugs. Almost $100 \%$ and $98.6 \%$ in III and II trimester respectively received iron. Other drugs prescribed were calcium, anti-emetics, anti-ulcer, NSAIDS and antimicrobial. The awareness about Intra Uterine Contraceptive Devices and Oral Contraceptive Pills were $48.2 \%$ and $31.5 \%$ respectively. Unfortunately only $4.9 \%$ felt that drug use could be dangerous to foetus. $58.9 \%$ were aware about antenatal examination during pregnancy.

Conclusions: Evaluation of drug utilization pattern periodically will minimize incidence of risk to foetus and mother during pregnancy.
\end{abstract}

Keywords: Drug utilization pattern, Pregnancy

\section{INTRODUCTION}

Pregnancy being altered physiological state affects the pharmacokinetics of medications used which put the foetus in potential risk. ${ }^{1}$ Hence prescribing in pregnancy is an unusual risk benefit situation. ${ }^{2}$ The concern on medication use during pregnancy and lactation has been influenced by historical events, including thalidomide crisis in the 1960s and the use of diethylstilboestrol in 1970. These events made US Food and Drug Administration to demonstrate safety and efficacy of any drug before it is marketed. ${ }^{3}$ Literature review revealed that less than $10 \%$ of medications approved by US Food and Drug Administration were determined for their teratogenic risks. ${ }^{4}$ However inspite of teratogenicity, it is unrealistic to recommend, not using any drugs at all during antenatal period.

Though pregnancy is a physiological condition still requires additional care and supplements such as folic acid, iron, calcium, vitamins and minerals, which plays pivotal role in the prevention of child and maternal morbidity and mortality. ${ }^{5}$ It has been noted that about $8 \%$ of pregnant women need permanent drug treatment due to 
various chronic disease and pregnancy induced complications. ${ }^{6}$ But unfortunately due to easy availability of drugs coupled with inadequate health services, increased proportions of drugs are used as selfmedications, as compared to the prescribed drugs which lead to adverse drug reactions and drug interactions during pregnancy. $^{7}$

Drug utilization studies can help in minimizing the inherent risk of drug used during pregnancy and also will provide insights regarding drug profile, existing health services and interventional measures. ${ }^{8}$ There are minimal studies conducted on drug utilization pattern in South India, this prompted me to study on drug utilization pattern in pregnancy at a tertiary care hospital in Puducherry.

Drugs play vital role in improving human health and promoting wellbeing. Therefore, judicious use of drugs, adequate knowledge, positive approach and awareness towards the drug use are necessary prerequisites for good maternal and child health. ${ }^{9}$ Safety of medicine prescribed to pregnant women has become major concern since the thalidomide tragedy in the 1960 s. ${ }^{10}$ This drug was widely used in the treatment of different disorders of anxiety, insomnia, gastritis, and tension; it was furthermore promoted as safe antiemetic drug during pregnancy. This drug was withdrawn from the market due to its severe teratogenic effects. ${ }^{9}$

Despite of all this, it is impossible to prevent medication use during pregnancy. There might be various comorbid conditions which need permanent medications. Therefore the benefit of medication therapy to the mother has to be weighed against the potential risk to the developing foetus. A study in north India reported that an average of 1.73, 2.89 and 2.49 drugs per pregnant women, were used during first, second and third trimester of pregnancy, respectively. ${ }^{6}$ A majority of drugs used, were from category-A, then category-B and category $D$. While category- $\mathrm{C}$ and category- $\mathrm{X}$ drugs constituted $2.90 \%$ and $5.71 \%$ of drugs used during third trimester and first trimester, respectively.

A study conducted in Sweden by assessing the prescribed drug register and the medical birth register showed that $57.6 \%$ purchased at least one prescribed drug during pregnancy. ${ }^{11}$ Agreement between drugs recorded in antenatal medical records and dispensed drugs were highest for drugs used for chronic conditions. Another study conducted at Manipal teaching Hospital in western Nepal of outpatient department reported that drugs used for nausea and vomiting is $4.7 \%$, dyspepsia is $3.1 \%$ and for vaginal bleeding is $3.4 \% .{ }^{12}$ Antiemetics were highly used in the first trimester and antacids in the second trimester of pregnancy.

Reviewed studies showed that medications used during pregnancy are prevalent and even some harmful drugs have been prescribed to pregnant women. The analysis of prescription pattern helps in understanding the type of medication used during pregnancy and safety of drugs used during pregnancy.

\section{METHODS}

The study was conducted at Department of Obstretics and Gynaecology (In and Out patient) and Department of Pharmacology at a tertiary care hospital.

It was observational cross sectional study.

Sample size was calculated using the formula $4 \mathrm{pq} / \mathrm{d}^{2}$ with $71.2 \%$ as the prevalence rate of category - A drug among the pregnancy women, $95 \%$ confidence interval and $10 \%$ non-response rate and it is $365 .^{13}$

Duration of the study was 3 months.

\section{Study pattern}

This prospective randomized cross sectional study (each pregnant woman was interviewed only once, regarding drugs used in their present pregnancy since conception) was conducted at Department of Obstretics and Gynaecology (in or out patient) and Department of Pharmacology at a tertiary care hospital.

The study was conducted after taking permission from the institutional ethical committee. Informed written consent was obtained from all the pregnant women who were willing to participate in the study and the prescribing doctor. The prescription slips were collected from the patients to obtain the demographic information, diagnosis and drugs prescribed. The drugs were further classified into category-A, category-B, category-C, category-D and category-X, according to the classification for drug use during pregnancy, introduced by the US Food and Drug Administration (FDA) in $1979 .{ }^{14}$

According to US FDA, category-A includes drugs that have shown no risk to the foetus after adequate, well controlled studies in pregnant women. For drugs in the category B, animal studies have revealed no evidence of harm to the foetus or any adverse effect, but adequate and well controlled studies in pregnant women have failed to demonstrate a risk to the foetus. The category $\mathrm{C}$ includes the drugs, which have shown an adverse effect in animal studies or no animal studies have been conducted and there are no adequate and well controlled studies in pregnant women. For drugs in the category D, there is positive evidence of human foetal risk, but the benefits from use in pregnant women may be acceptable despite the risk (e.g., in a life-threatening situation). However, drugs with classification X are "contraindicated in pregnancy".

Using a structured questionnaire, the patients were interviewed personally in their local language and confidentiality was maintained throughout the study. Various parameters like knowledge about antenatal visit, drugs used during pregnancy, self-medication practices; 
knowledge about contraception was assessed in the pregnant woman.

\section{Statistical analysis}

The data was analysed using Epi Info software version 3.5.3 and was expressed as percentage. Inter- group comparison was performed using Chi- square test. $\mathrm{P}$ value $<0.05$ was considered as statistically significant.

\section{RESULTS}

Totally 365 pregnant women who gave voluntary consent during the antenatal visit were included in the study. Majority of the participants were in the reproductive age group of 22-25: $47.2 \%, 44.6 \%$ and $38.4 \%$ in first, second and third trimester respectively (Table 1). Among them52.2\% in second trimester, $63.2 \%$ in first trimester and $46.3 \%$ in third trimester were primigravida and $53.7 \%$ in third trimester, $47.8 \%$ in second trimester, $36.8 \%$ in first trimester were multi gravida. Out of total study participants 297 participants $(81.4 \%)$ have finished their high schooling and nearly $87.7 \%$ were there in first trimester, whereas $82.6 \%$ and $75.4 \%$ were in their third and second trimester respectively. Only $0.3 \%$ of the antenatal women were illiterates in this study. Most of the pregnant women were housewives, in that $93.4 \%$ in third trimester, $92.5 \%$ in first trimester and $92 \%$ in the second trimester.

Table 1: Demographic characteristics of pregnant women attending antenatal clinic.

\begin{tabular}{|lll|l|}
\hline Parameters & $\begin{array}{l}\text { First } \\
\text { trimester } \\
\mathbf{n}(\%)\end{array}$ & $\begin{array}{l}\text { Second } \\
\text { trimester } \\
\mathbf{N}(\%)\end{array}$ & $\begin{array}{l}\text { Third } \\
\text { trimester } \\
\mathbf{n}(\%)\end{array}$ \\
\hline Age & & & \\
\hline $18-21$ & $8(7.5)$ & $21(15.2)$ & $7(5.8)$ \\
\hline $22-25$ & $50(47.2)$ & $53(38.4)$ & $54(44.6)$ \\
\hline $26-28$ & $42(39.6)$ & $45(32.6)$ & $45(37.2)$ \\
\hline $29-32$ & $6(5.7)$ & $19(13.8)$ & $15(12.4)$ \\
\hline Gravida & & & \\
\hline Primigravida & $67(63.2)$ & $72(52.2)$ & $56(46.3)$ \\
\hline Multi gravida & $39(36.8)$ & $66(47.8)$ & $65(53.7)$ \\
\hline Literacy & & & \\
\hline Illiterate & $0(0)$ & $1(0.7)$ & $0(0)$ \\
\hline Schooling & $13(12.3)$ & $31(22.5)$ & $21(17.4)$ \\
\hline High schooling & $93(87.7)$ & $104(75.4)$ & $100(82.6)$ \\
\hline Graduate & $0(0)$ & $2(1.4)$ & $0(0)$ \\
\hline Occupation & & & \\
\hline House wife & $98(92.5)$ & $127(92)$ & $113(93.4)$ \\
\hline Working & $8(7.5)$ & $11(8)$ & $8(6.6)$ \\
\hline
\end{tabular}

Values were expressed as percentage $(\%) ; n=$ total number of participants

The most commonly prescribed drug in first, second and third trimester were iron, calcium, folic acid, which were category A drugs (Table 2). Usage of iron in second trimester was $98.6 \%$, whereas iron was not prescribed in first trimester. Folic acid usage was $100 \%$ in first trimester, $99.3 \%$ in second trimester and $5.8 \%$ in third trimester. Usage of calcium was $98.6 \%, 96.7 \%, 0.9 \%$ in second, third and first trimester respectively. Category B drugs usage during antenatal period were $3.6 \%$ in first trimester, $1.7 \%$ in second trimester and $3.6 \%$ in third trimester. Only $0.9 \%$ and $0.5 \%$ use of Category $\mathrm{C}$ drugs was in first and second trimester respectively, whereas category $\mathrm{C}$ drugs were not prescribed in third trimester.

Table 2: Percentage distribution of drugs in pregnant women according to FDA categories.

\begin{tabular}{|c|c|c|c|c|}
\hline $\begin{array}{l}\text { Category } \\
\text { of } \\
\text { Drugs }\end{array}$ & $\begin{array}{l}\text { First } \\
\text { trimester } \\
\text { t.n.d= } \\
112 \\
\text { n(\%) }\end{array}$ & $\begin{array}{l}\text { Second } \\
\text { trimester } \\
\text { t.n.d= } \\
\mathbf{4 1 8} \\
n(\%)\end{array}$ & $\begin{array}{l}\text { Third } \\
\text { trimester } \\
\text { t.n.d = } \\
252 \\
\text { n(\%) }\end{array}$ & $\begin{array}{l}\text { p- } \\
\text { value }\end{array}$ \\
\hline A & $\begin{array}{l}107 \\
(95.5)\end{array}$ & $\begin{array}{l}409 \\
(97.8)\end{array}$ & $\begin{array}{l}243 \\
(96.4)\end{array}$ & $* 0.0379$ \\
\hline B & $4(3.6)$ & $7(1.7)$ & $9(3.6)$ & 0.2455 \\
\hline $\mathrm{C}$ & $1(0.9)$ & $2(0.5)$ & $0(0)$ & \\
\hline $\mathrm{D}$ & 0 & 0 & 0 & \\
\hline$X$ & 0 & 0 & 0 & \\
\hline
\end{tabular}

$\mathrm{n}=$ number of drugs; t.n.d= total number of drugs . Values were expressed as percentage (\%); ${ }^{*} \mathrm{p}<0.05$ was considered statically significant. $\mathrm{P}$ value was calculated after comparing value between first, second and third trimester by using Chi- square test with degree of freedom 2.

In this study duration none of the pregnant women were included category D or X drugs. Usage of category A drugs was significantly more insecond trimester compared to first and third trimesters. No significance difference was observed with category B drug usage among all the three trimesters. $98.6 \%$ in second trimester and $100 \%$ in third trimester received iron (Figure 1).

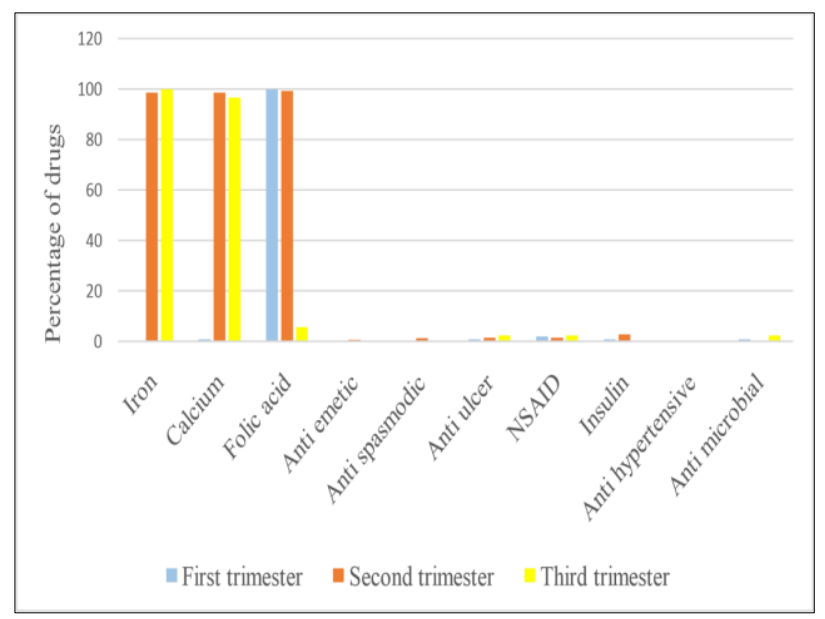

Values were expressed as percentage $(\%)$

\section{Figure 1: Pattern of drug used in pregnant women attending antenatal clinic.}

Around $0.9 \%$ first trimester, $98.6 \%$ second trimester and $96.7 \%$ third trimester had taken calcium. Usage of folic acid in first trimester was $100 \%$, in second trimester $99.3 \%$ 
and in third trimester $5.8 \%$. Anti-emetic usage was $0.7 \%$ in second trimester only. $1.4 \%$ of antispasmodic was used in second trimester. Anti-ulcer was prescribed to $0.9 \%$ of first trimester, $1.44 \%$ of second trimester and $2.47 \%$ of third trimester. Around $1.9 \%, 1.45 \%$ and $2.47 \%$ NSAIDs have been used by first, second and third trimester respectively. Insulin was prescribed to $0.9 \%$ in first trimester, $2.89 \%$ in second trimester participants. Only $2.5 \%$ third trimester women used anti-microbial. None of our study participants received anti-hypertensive.

Awareness about intra uterine devices (IUCDs) and Oral contraceptive pills (OCP) were $48.2 \%$ and $31.5 \%$ respectively (Figure 2). Around $20.3 \%$ were not aware of various methods of contraceptives and unexpectedly none of the knew about injectable contraceptive.

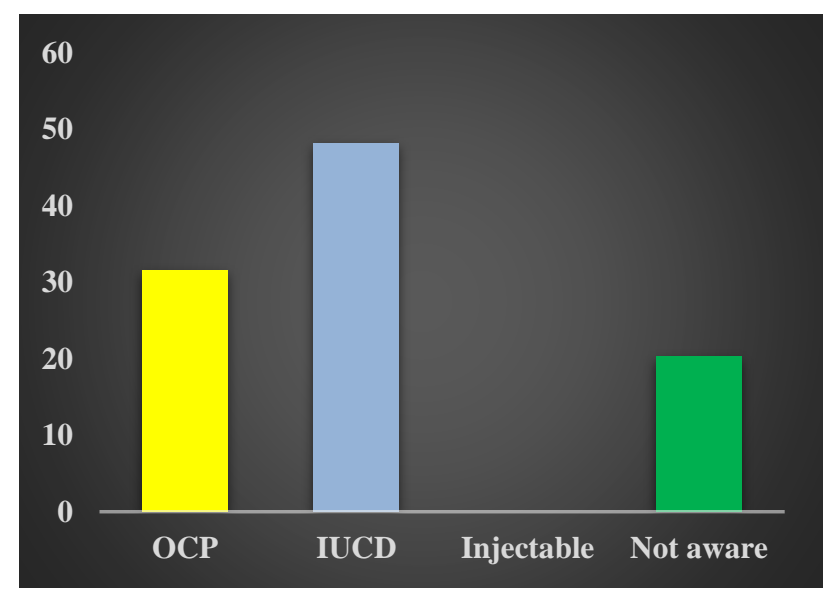

Figure 2: Awareness of study population about various methods of contraception.

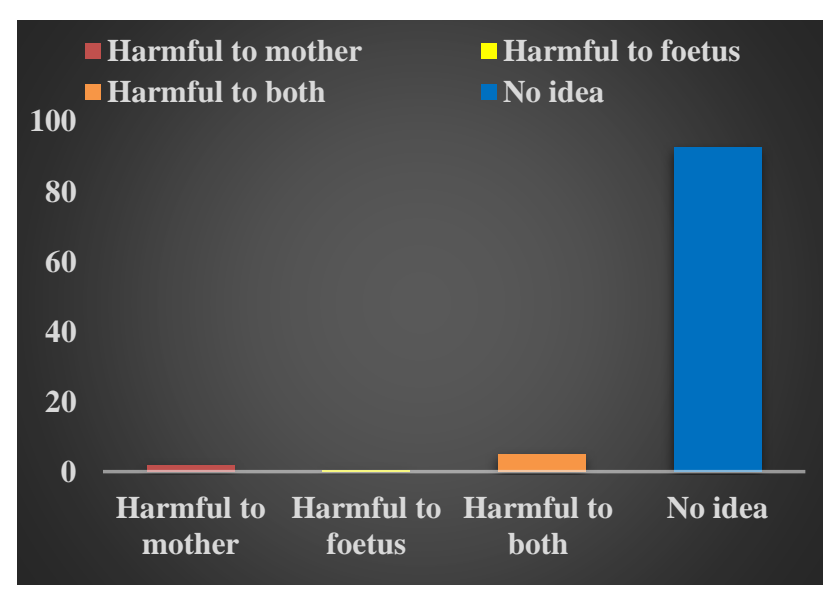

Values were expressed as percentage (\%)

\section{Figure 3: General understanding of study population about drug use in pregnancy.}

Among the participants, $92.6 \%$ had understanding about drug use in pregnancy whereas $1.9 \%$ and $0.5 \%$ of study participants thought it could be harmful to mother and harmful to baby respectively (Figure 3). Only $4.9 \%$ were able to tell, drugs used during pregnancy could be dangerous to mother and foetus. Awareness about antenatal examination among the study population were only $58.9 \%$ (Figure 4).

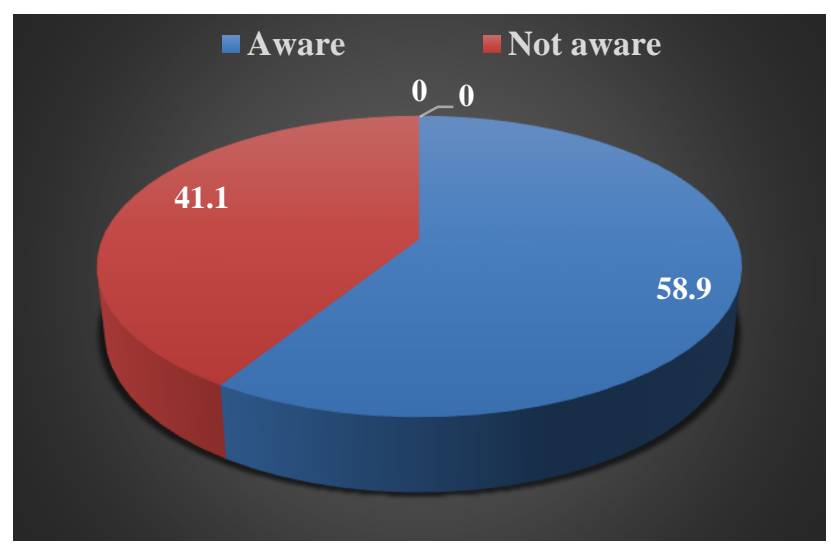

Values were expressed as percentage (\%)

Figure 4: Awareness of antenatal examination among antenatal women.

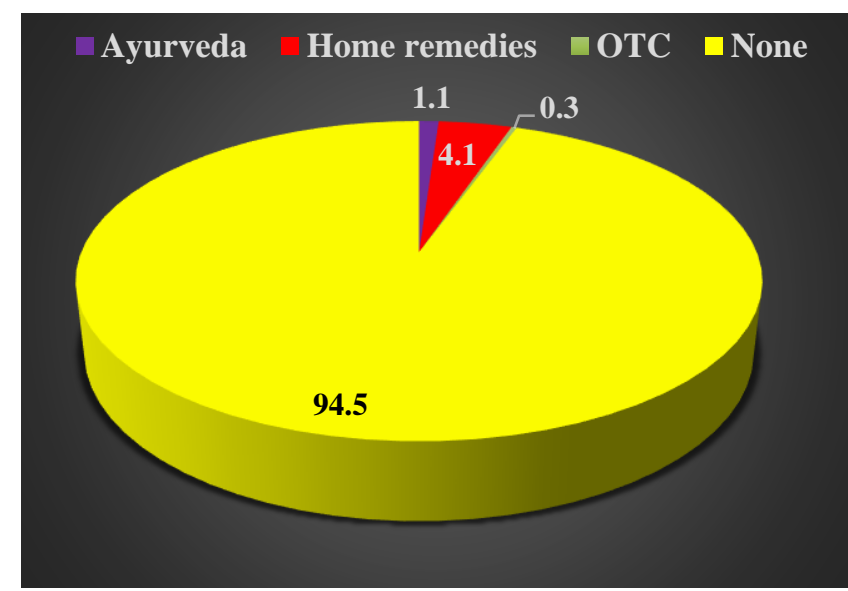

Values were expressed as percentage (\%)

Figure 5: Self- medication practices in antenatal women.

\section{DISCUSSION}

The inherent risk of drug use during pregnancy can be minimized by doing drug utilization study and it also provides knowledge about drug profile in existing health services. In this study among 365 pregnant women attending antenatal clinic, $43 \%$ were in age group of 22 to 25 years which represents the normal reproductive age group. ${ }^{7}$ This is in accordance with the observation made by an Indian study by Rathnakar et al. ${ }^{15,16}$ None of our participants were below the age group of 18. Most of our study participants have done their high schooling (81.4\%). This finding is similar to the study done in Ethiopia by Mesfin et al. ${ }^{17}$

The FDA category A drugs prescribed for antenatal women include ferrous sulphate, folic acid, calcium, multi vitamins and vitamin B complex. These comprised $95.5 \%$ in first trimester, $97.8 \%$ in second trimester rand $96.4 \%$ in third trimester in present study. In contrast the study 
conducted in the USA revealed that only $2.4 \%$ of category A drugs were prescribed to their study participants. ${ }^{18}$ According to the WHO, 6 months regimen of daily supplement containing $60 \mathrm{mg}$ of elemental iron along with 400 micro grams of folic acid is necessary for all pregnant women. ${ }^{19}$ In areas with higher prevalence of anaemia, it is recommended that supplementation should include for 3 months postpartum. And also in 2011 the WHO recommended calcium supplementation with 1.5-2.0 grams elemental calcium daily for pregnant women in areas with low dietary calcium. ${ }^{20}$ Thus intake of Iron, calcium and folic acid during pregnancy is mandatory especially in developing countries like India. In this study about $3.6 \%$ first trimester, $1.7 \%$ second trimester and $3.6 \%$ third trimester were prescribed drugs from category B. ${ }^{16} \mathrm{It}$ is similar to the study done by Joshiet al. Very low percentage of antenatal women received category $\mathrm{C}$ drugs in first trimester and second trimester inour study. It is relatively less compared to the study done in USA, where $37.8 \%$ of category $\mathrm{C}$ drugs were prescribed. ${ }^{18}$ None of our study participants received category $\mathrm{D}$ and $\mathrm{X}$ drugs which shows the ethical prescribing behaviour among the physicians during our study period. In contrast, a study done at Ethiopia revealed that use of category $\mathrm{D}$ and $\mathrm{X}$ where $9.43 \%$ and $1.09 \% .{ }^{17}$ And in other study done in India, the use of category D drugs where $6 \%, 0.09 \%$ and $12.54 \%$ in first, second and third trimester respectively and category X drugs was $5.71 \% .^{6}$

In the present study use of drugs as self-medication was reported significantly low. This is not similar to other studies conducted. Earlier also, in a study from USA, OTC medication (example- ibuprofen) that are contraindicated were used at unexpectedly high rates during pregnancy. ${ }^{21}$ Knowledge about contraceptive is important to prevent infections like HIV and other STDs, in a woman of child bearing age. In the present study $48.2 \%$ have knowledge about IUCDs. But unfortunately, none of the antenatal women were aware of injectable as contraceptive. This is in contrast with the study done in Pakistan by Hannah et al, which revealed that around $16 \%$ of their study population had awareness about injectable as contraceptive, and they also stated that contraceptive use was common among the women with more education, higher wealth status and also who had counselling given by health workers, family and friends. ${ }^{22}$

Reinforcing postnatal counselling regarding contraceptive to all mother and implementing strategies that address contraceptive needs in unmarried women, creating awareness on contraceptives at community level is necessary to reduce the rate of pregnancy. ${ }^{23}$ The general understanding of drug use in pregnancy is relatively low. Around $92.6 \%$ pregnant women were not aware of drug use in pregnancy could be dangerous to both mother and child. Study revealed that awareness about antenatal examination was around $58.9 \%$.

Safer prescription practice among physician will reduce the incidence of risk to foetus and mother. Our study revealed that there was ethical prescribing pattern among the physician during our study duration. There should be counselling and education during pregnancy to overcome the lack of awareness on safety of drugs in pregnancy and awareness about antenatal examination, which was observed in this study.

Limitations of the study where it was conducted only in single tertiary care hospital for a shorter duration of 3 months. Further, the study did not measure the pregnancy outcome as it was an observational study. So, if it is done in multiple health care centres for a large duration, reliable data can be obtained, and it can provide rational benefit to the society.

\section{CONCLUSION}

In this study, many of the study participants belong to the reproductive age group of 22-25 years. The positive findings in this studies are many of our study participants had completed their high schooling, use of category D and $\mathrm{X}$ drugs and self-medication were relatively low. According to our study awareness about contraceptive were not adequate. Especially none of the antenatal women from our study population were aware of injectable contraceptive. Knowledge about drug used in pregnancy can be dangerous to both mother and child and awareness about antenatal examination was poor. This can be overcome by given counselling session to antenatal women.

\section{ACKNOWLEDGEMENTS}

The authors would like to thank ICMR for having funded this project. We would also like to thank the management and Director for providing us with the support needed to do the study.

\section{Funding: Funding sources from ICMR Conflict of interest: None declared \\ Ethical approval: The study was approved by the Institutional Ethics Committee of ICMR}

\section{REFERENCES}

1. Deborah E, Mc Carter, Spaulding MS. Medications in pregnancy and lactation. Amer J Maternal Child Nursing. 2005;30:10-7.

2. Uchenna IE, Adego EE, Azuka CO, Ehijie FE. Assessment of Prescription profile of pregnant women visiting antenatal clinics. Pharmacy Practice. 2007;5(3):135-9.

3. Sachdeva P, Patel BG. Drug use in pregnancy; a point to ponder Indian J Pharm Sci. 2009;71:1-7.

4. Adam MP, Polifka JE, Friedman JM. Evolving knowledge of the teratogenicity of medications in human pregnancy. Am J Med Genet 2011;157:175-82.

5. Blot I, Papiernik E, Kaltwasser JP, Werner E, Tchernia $\mathrm{G}$, Influence of routine administration of folic acid and 
iron during pregnancy. Gynecol Obstet Invest. 1981;12:294-304.

6. Sharma R. Kapoor B, Verma U. Drug Utilization Pattern during pregnancy in North India. J Med Sci. 2006;60:277-87.

7. Sorensan MK, Philips BB, Mutnick AH. Drug use in specific patient population: pediatric, pregnant, geriatric in: Shargel L. Mutnick A, editors. Comprehensive Pharmacy Review, $5^{\text {th }}$ Ed. Philadelphia, Lippincott William Wilkins; 2008:673682.

8. Kraemer K. Placental transfer of drugs. Neonatal Network. 1997;16:65-7.

9. Kallen BA. Methodological issues in the epidemiological study of the teratogenicity of drugs. Congenital Anomalies. 2005;45:44-51.

10. Koren G, Pastuszak A, Ito S. Drugs in pregnancy. New England Journal of Medicine. 1998;2(7):547-54.

11. Stephansson O, Granath F, Svensson T, Haglund B, Ekbom A, Kieler H. Drug use During pregnancy in Sweden - assessed by the Prescribed Drug Register and the Medical Birth Register. Clinical Epidemiology. 2011;3:43-50.

12. Das B, Sarkar C, Datta A, Bohra S. A study of drug use during pregnancy in a teaching hospital in western Nepal. Pharmacoepidiology and drug safety. 2003;12:221-5.

13. Kureshee NI, Dhande PP. Awareness of Mothers and Doctors about Drug Utilization Pattern for Illnesses Encountered during Pregnancy. JCDR. 2013;7:24704.

14. FDA class: Drugs in Pregnancy and Lactation, $5^{\text {th }} \mathrm{Ed}$ Wilkins and Wilkin: Baltimore; 1998.

15. Rathnakar UP, Singh N. Drug utilization patterns drug antenatal period, Journal of Pharmacy Research. 2011;4(10):3359-561.

16. Joshi H, Patel S, Patel K, Patel V. Drug use Pattern during pregnancy: A Prospective study at Tertiary Care Teaching Hospital. NHL Journal of Medical Science. 2012;1(1):14-7.

17. Filcadu M, Kebebe D, Amelo W, Gashe F. Drug Utilization Pattern and Potential Teratogenicity Risk among Pregnant Women Visiting Antenatal clinic. The case of primary hospital. NHL Journal of Medical Science. 2012;1(1):27-33.

18. Andrade SE, Gurwitz JH, Davis RL, Chan KA, Finkelstein JA, Fortman K, et al. Prescription hospital drug use in pregnancy. Am J Obstet Gynecol. 2004;191(2):398-407.

19. World Health Organization (WHO), Iron deficiency anaemia; assessment, prevention and control: a guide to programme managers, WHO /NHD/ 01.3, 2001. Available at: http: // www.who.int/nutrition/ publications/ en / ida_assessment_prevention_ control. Pdf.

20. Von Dadelszen P, Firoz T, Donnay F, Gordan R, Hofmeyr GJ, Lalani S, et al. Preeclampsia in low and middle-income countries- health services lessons learnt from the PRE-EMPT (PRE-eclampsiaEclampsia Monitoring, Prevention and Treatment) project. J Obstet Gynaecol Can. 2012;34:917-26.

21. Drhova L. Knowledge, attitudes, and behaviour of the population of the Czech Republic to self-medicationII. Knowledge of and information about drugs. CeskaSlov Farm. 2005;54:168-72.

22. Mohmmed F, Musa A, Amano A. Prevalence and determinants of unintended Pregnancy among pregnant woman attending ANC at Gelemso General Hospital, Oromiya Region, East Ethiopia: A facility based cross-sectional study. BMC Women's Health 2016;16:56

23. Tappis H, Kazi A, Hameed W, Dahar Z, Ali A, Agha $\mathrm{S}$. The role of quality health services and discussion about birth spacing in postpartum contraceptive use in Sindh, Pakistan: a multilevel analysis. PloS one. 2015 Oct 20;10(10):e0139628.

Cite this article as: Selvaraj N, Sekar A, Gandhi R, Jayabalan N, Ganesan S, Mohammad ASR. Drug utilization pattern in pregnancy at a tertiary care hospital in Puducherry: a cross sectional observational study. Int J Basic Clin Pharmacol 2018;7:900-5. 